\title{
"How Far Have We Reached with Regards to Our Endeavours in Testicular Tissue Transplantation Along with in Vitro Spermatogenesis After Success in Animals - A Systematic Review"
}

\author{
Dr. Kulvinder Kochar Kaur, MD¹, Dr. Gautam Allahbadia, MD (Obstt \& Gynae), D.N.B ${ }^{2}$, \\ Dr. Mandeep Singh, MD, DM.(Std) (Neurology) ${ }^{3}$
}

${ }^{1}$ Scientific Director, Dr Kulvinder Kaur Centre For Human Reproduction, Punjab, India.

${ }^{2}$ Scientific Director, Ex-Rotunda-A Centre for Human Reproduction, Mumbai, India.

${ }^{3}$ Consultant Neurologist, Swami Satyanand Hospital, Punjab, India.

*Corresponding Author: Dr. Kulvinder Kochar Kaur, MD, Scientific Director, Dr Kulvinder Kaur Centre For Human Reproduction, Punjab, India.

\begin{abstract}
After reviewing the role of very small stem cells role in both male and female fertility with regards to oncofertility, here we tried to explore what can be done with regards to more problems in relation to male infertility say cases of azoospermia, in cases of transgender males, especially oncofertility where prepubertal boys are concerned. Here we have reviewed work done on testicular tissue preservation and transplantation in both adult and prepubertal boys, more so research that has been successfully conducted in animals and whatever is the latest research on humanbeings. We conducted a systematic review utilizing pubmed search engine, google scholar, embase, Cochrane library, web of science and looked for MeSH terms like Spermatogonial Stem Cells; cryopreservation; males undergoing therapy for malignancies both prepubertal and adults; transgender females; kline felter syndrome; azoospermia with maturation arrest; testicular tissue cryopreservation; testicular tissue immature; mature testicular tissue; autologous transplantation; xenografting; various animal species like nonhuman primate studies; rodent; from 1990-2020 till date. We found a total of 1250 articles out of which we selected 100 articles for this review. No meta-analysis was conducted. Once safety has been achieved after animal studies time has come for this to reach the clinical scenario. The best that has been achieved in humans is cryopreservation of immature testicular tissue in prepubertal boys although till now no successful sperm production in humans has been reported. We are waiting for the day when even males having round spermatids might be utilized and how we can utilize SSC'S, VSEL's present in niche around the sertoli cells as reviewed earlier and hopefully that day is not far.
\end{abstract}

Keywords: Spermatogonial Stem Cells; cryopreservation; transgender females; immature testicular tissue cryopreservation; Cell Suspension; Xenografting; Aoutologous transplantation.

\section{INTRODUCTION}

Following the birth of $1^{\text {st }}$ in vitro fertilization (IVF) child in 1978, with artificial reproductive technology( ART) era initiated nearly 8million children got conceived as well as born with ART. [1] As far as men with azoospermia /oligozoospermia, are concerned, ART is a good option. Nevertheless, for the men who have the inability of forming a mature sperm secondary to congenital disorders, acquired diseases/ gonadotoxic therapies, there are no fertility options existing. Currently infertility research is focusing on innovative methods getting discovered as well as refining them for utilizing them in future for aiding these men in attaining an offspring. Despite none has managed to enter clinically, their outcomes in mammals have been assuring. Here we review experimental stem 
"How Far Have We Reached with Regards to Our Endeavours in Testicular Tissue Transplantation Along with in Vitro Spermatogenesis After Success in Animals - A Systematic Review"

cell as well as testicular tissue -based methods with infertility in mind as well as detail further work required for these methods to ultimately to be of use clinically.

\section{Spermatogonial Stem Cells as Well as SPERMATOGENESIS}

Spermatogonial Stem Cells (SSCs), represent the maximum primitive kind of Spermatogonia, are observed on the basement membrane (BM) of seminiferous tubules as well as have the properties of self renewal as well as differentiation. For sustainance of Spermatogenesis continuously right throughout life span appropriate functioning of SSCs is needed [2]. In the basal compartment of the seminiferous tubules a population of Spermatogonia, that can be further broken up into type A intermediate as well as B subpopulation. In cases of primates, undifferentiated type A Spermatogonia, that possess all SSCs, get further subdivided into $A$ dark $\left(A_{d}\right)$ as well as $A_{\text {pale }}\left(A_{p}\right)$ subtypes [3]. For a considerable time it was thought that both $A_{d}$ as well as $A_{p}$ represented morphologically as well as histologically 2 separate populations of cells having distinct parts, i)reserve Stem Cells $\left(A_{d}\right)$ as well as active Stem Cells $\left(A_{p}\right)$ which undergo self renewal as well as differentiation, for sustainance of steady Spermatogenesisincaseofadulttestis[4].Nevertheless, current work has pointed that a minimum of certain $\left(A_{d}\right)$ as well as $\left(A_{p}\right)$ cells are rather than from same populations but at various stages from the same stages of the cell cycle[5]. Differentiation as well as renewal of SSCs in the seminiferous tubules get controlled through the surrounding stem Cells niche (figure1) [6], a dynamic microenvironment made up of sertoli cells as well as the testicular interstitial cells as well as generate molecular signals to modulate SSCs function [7]. In view of relatively few SSCs present within testis as well as absence of definitive SSCs markers, isolating the exact anatomic placing of the niche has proved problematic [8,9]. Nevertheless, earlier mouse studies have pointed that the SSCs placement along the basement membrane of seminiferous tubules might be concentrated in areas next to the blood vessel's as well as surrounding interstitium [10], pointing that blood borne substances, vascular endothelial cells (VEC's), as well as paracrine products of different interstitial cells kinds (that include leydig cells, peritubular cells as well as macrophages) are essential for normal SSCs working [7].

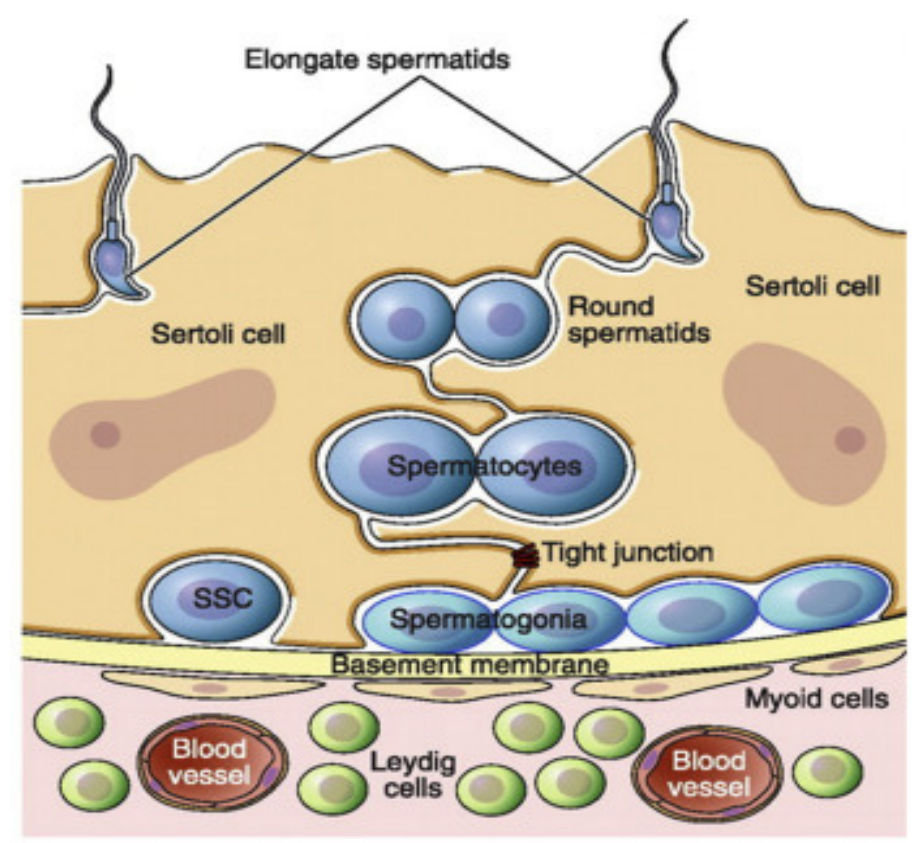

Figure1. Courtesy reference number -6- The adult spermatogonial stem cell niche. Spermatid formation occurs within the seminiferous tubules. Spermatogonial stem cells and other undifferentiated spermatogonia associate with the basal seminferous tubule epithelium in close proximity to Sertoli cells, Leydig cells, blood vessels, and other interstial cells, together providing the necessary microenvironment for spermatogonial differentiation. This process occurs in the luminal compartment, which is separted from the basal layer by tight junctions. 
"How Far Have We Reached with Regards to Our Endeavours in Testicular Tissue Transplantation Along with in Vitro Spermatogenesis After Success in Animals - A Systematic Review"

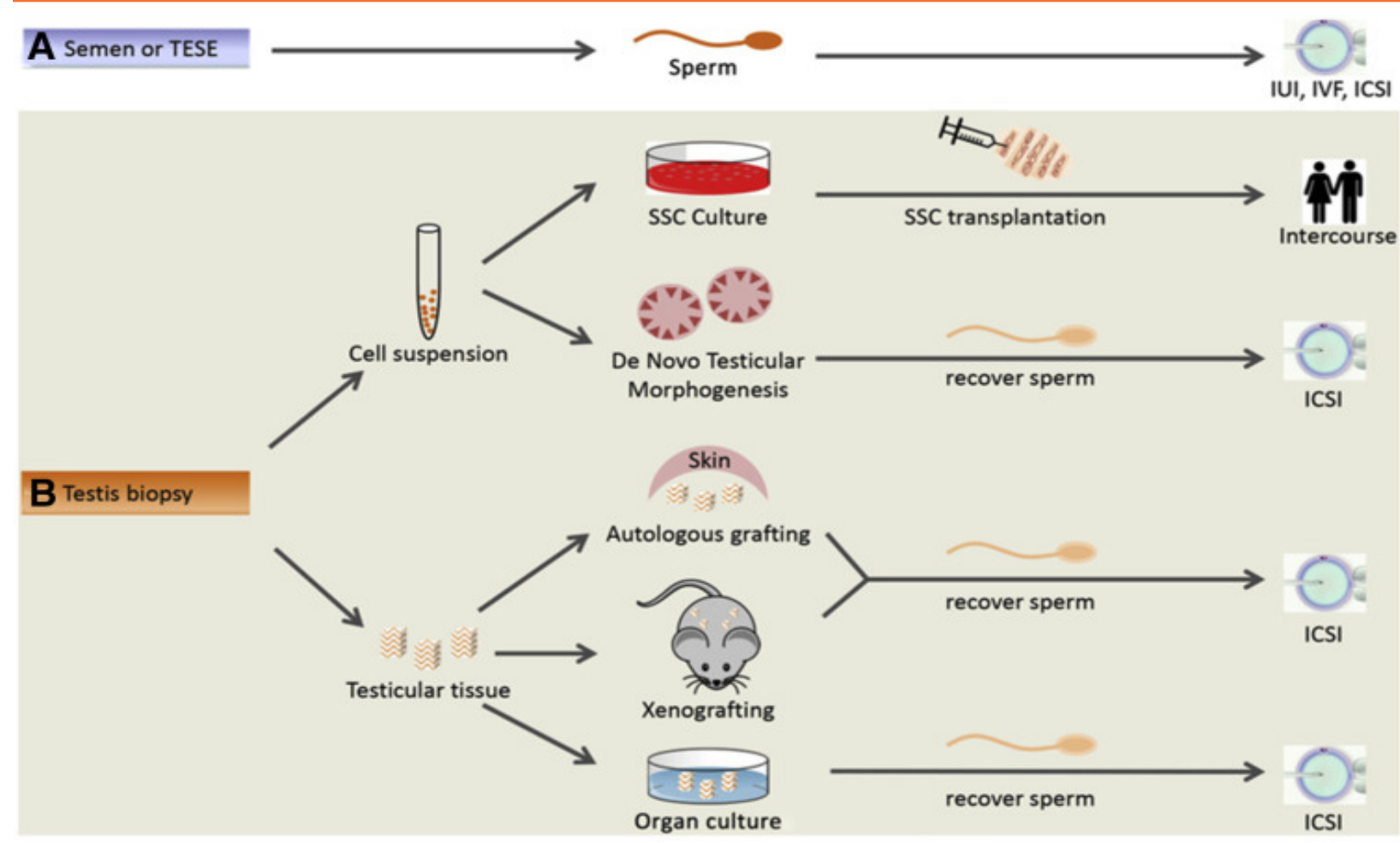

Figure2. Courtesy reference number -6-Current experimental therapies for male infertility. (A) If semen or extract sperm cells are available, intrauterine insemination, in vitro fertilization, and intracytoplasmic sperm injection are possible. (B) When obtaining sperm is not possible (e.g., infertility after chemotherapy), testicular tissue can be obtained via testis biopsy. Tissue that is enzymatically digested can be used to form a spermatogonial stem cell culture that can be reimplanted into the testis to allow for natural fertility. Heterogeneous cell suspensions can also undergo de novo testicular morphogenesis to form functional seminiferous tubules that allow for sperm production and subsequent intracytoplasmic sperm injection. Whole testicular tissue may be autologously grafted or xenografted into mice to produce functional sperm. Alternatively, testicular tissue can be cultured in a specialized medium to produce sperm in a process known as in vitro spermatogenesis.

\section{Fertility Preservation in the Male}

A lot of situations as well as their correlated therapies might reduce SSCs function or the Stem Cells niche, ultimately landing up in subfertility or infertility. Though oncology patients serve as best e. g's a lot of patients that include those receiving immunosuppressive agents as well as transgender persons might have advantage with Fertility Preservation (FP) [11].

Once the cancer survival rates as well as parallel survivorship in reproductive age, FP has become a necessary part of oncology treatment [12]. Rapidly proliferating cells like Spermatogonial cells in the testis have sensitivity to the cytotoxic actions of radiation as well as particular chemotherapies (especially alkylating or platinum based agents-as per a lot of cancer treatment regimens can cause impairment in fertility [13]. Of the childhood survivors of cancers, $48 \%$ documented infertility with $52 \%$ had a sperm count $<15$ million $/ \mathrm{ml}$ in long term follow up examinations [14]. Due to this, the American Society of Clinical Oncology, American Academy of Pediatrics, as well as American Society of reproductive Medicine (ASRM), all advocate pre treatment FP counselling in patients that are going to undergo gonadotoxic therapies $[12,15]$.

Inspite of this high prevalence of treatment-stimulated infertility, only $29 \%$ of male cancer patients documented discussing FP with their oncologists, along with $11 \%$ going on to sperm banks [16]. Knowledge of the gonadotoxic properties of many nononcologic immune therapies like hydroxyurea or siromilus as well as hormonal or surgical treatment for gender dysphoria FP, needs to be taken into account for these patient populations also [17]. Methods of FP need to be based on a patients sexual maturity level. 
"How Far Have We Reached with Regards to Our Endeavours in Testicular Tissue Transplantation Along with in Vitro Spermatogenesis After Success in Animals - A Systematic Review"

\section{Adult}

The best method that has got recognition as well as is preferred for FP in case of postpubertal males is the cryopreservation of the ejaculated semen received via masturbation, that usually $90 \%$ of the patients can manage of those looking for FP [18]. Despite the protocols for various institutions differ, but classically 2-3 samples are collected either in office or at home, with $48 \mathrm{~h}$ abstinence periods among collections [19]. Semen can continue to be cryopreserved or frozen as well as can be utilizable for yrs, with multiple live births, documented for over $20 \mathrm{yrs}$ following the initial recovery [20] as well as one live birth (LB) from a sample that had been preserved for $>40 \mathrm{yrs}$ [21]. A huge meta analysis conducted on 801 patients displayed a $49 \%$ LB success rate for the men who preferred to utilize cryopreserved sperm [22]. Long periods of storage of sperms did not have any adverse action on live birth rates ( LBR), with similar rates observed at 5, 10 live birth 15yrs of cryopreservation[23].

While semen sample retrieval through masturbation, is best, certain men are either too unwell or are not ready to provide a sample in this way. Men with anorgasmia or anejaculation following neurologic or separate medical problems, pelvic or retroperitoneal surgery, or psychogenic reasons might have advantage by other methods of retrieval of sperms. Both electroejaculation as well as penile vibratory stimulation represent noninvasive methods for collection of semen in such patients [24]. Surgical testicular sperm extraction is just preferred for azoospermic patients or men who fail following less invasive methods $[25,26]$.

\section{Adolescent/Peripubertal}

Basic principle of FP in Adolescent boys are Basically similar to that in Adults, while keeping certain extra points in mind. A lot of younger peripubertal patients are sexually novice, in which tough discussions among patients, parents live birth providers might occur [27]. Thus, talking to both patients as well as parents, at individual level or together, are essential for tackling this problem with success [28]. Ethical problems particular to Adolescent, like, parents versus patients ability to be able to make decisions, might occur, that brings in the role of a medical ethicist [29]. Nevertheless, arriving at a decision FP should be done fast, with high success rates, with upto $65 \%$ of patients between 11-13yrs while $80 \%$ among 14-17yrs age can successfully cryopreserve sperms[30]. For those Adolescent patients having inability to collect or are not ready to produce a semen sample, Testicular sperm aspiration (TESA) or testicular biopsy are good methods.

\section{Prepubertal}

When patients are prepubertal and thus have no initiation of Spermatogenesis, only experimental methods are present for cryopreservation of testicular tissue retrieved by testicular biopsy or orchiectomy. Despite successful restoration of fertility following cryopreservation, has not yet been shown in humans, various centres across world have managed to collect as well as cryopreserved testicular biopsied testicular tissue [31, 32], with the anticipation of experimental stem cell as well as testicular tissue -based methods would make this feasible in future.

\section{Testicular Material Cryopreservation}

Even in 1776 the idea of sperm cryopreservation was realized 1776 by the Italian scientist Lazzaro Spallanzani observed that sperms became motionless on cooling in snow [33]. More research during mid-20 $0^{\text {th }}$ century, markedly advanced regards to cryoprotectants like glycerol got evaluated as well as used for livestock artificial insemination techniques. For cryopreservation to be of success, is based on freezing to temperatures which halt the cellular metabolism, although these temperatures further result in escalated reactive oxygen species(ROS), injury to organelle, as well as caspase -mediated apoptosis that reduces the sperm fertility potential[34]. Rest few studies have shown stat significant decrease in post thaw morphology [35], motility[36] as well as DNA integrity [37]. Hence, it demands key research for finding the ideal protocols for cryopreservation for getting the highest success in sperm retrieving as well as function.

Very little work has been done regards to contrasting the post thaw actions of different cryoprotectants in humans. Though some newer substances have been evaluated as well as displayed appreciation [38], dimethyl sulfoxide continues to be standard cryoprotectants in a lot of Ameriacan as well as European FP centers [39] for prepubertal boys. Both slow freezing as well as vitrification protocols have been compared as well. Vitrification utilizes various cryoprotectants amounts as well as ultrarapid 
"How Far Have We Reached with Regards to Our Endeavours in Testicular Tissue Transplantation Along with in Vitro Spermatogenesis After Success in Animals - A Systematic Review"

cooling for avoiding ice crystals generation. A metaanalysis recently compared these 2 protocols [40], demonstrated enhanced post thaw parameters in the cohort belonging to Vitrification. Rest of the studies have confirmed this observation [38, 40], as well as the 1st LB following intracytoplasmic sperm injection (ICSI) utilizing Vitrified sperms has been recently documented [41]. Nevertheless, just 2 trials small in nature have evaluated the possibility of Vitrification for immature testicular tissue, thus reducing its clinical application in this setting [42]. As per these studies a lower amount of cryoprotectant in Vitrification protocols might reduce organelle, as well as membrane injury, as well as ultimately enhance sperm survivalness.

\section{Cell Suspension vs Testicular Tissue}

2 approaches are present for long term preservation of SSCs i) cryopreservation of Testicular tissue (TT), or Testicular cell Suspension. cryopreservation of TT fragments utilizing Vitrification or slow - freezing protocols depends on permeable cryoprotectant, might result in cellular injury. Moreover use of macroscopic testicular tissue samples, like in TT, adds heat as well as mass transfer at the time of freezing, which results in ununiform cooling rates as well as later alterations in cell-cell crosstalk [43]. Such biophysical transfer processes are Significantly decreased on utilizing microscopic SSCs storage. 1 main advantage of TT, never is storage of SSCs niche architecture, that might enhance, post thaw SSCs viability as well as function [44].

In humans Testicular cell Suspension preservation/ storage has not been that well evaluated in human beings (45], with only Yango et al. [46], talked about the possibility of this technique for prepubertal fetal Testicular cells. Appropriate preparation of Testicular cells Suspensions need mechanical separation, enzymatic digestion, as well as cellular filtering to provide Testicular cells [47]. Minimal comparative research presence, one cant at present find the ideal method of utilizing Testicular tissue vis a vis cell Suspension. Nevertheless, freezing Testicular tissue as such intact stores both the availability of either tissue -dependent or cell - dependent therapies in the future. cryopreservation of Testicular cell Suspension removes the option of tissue -dependent treatment in the future, like Testicular tissue grafting or Testicular tissue organ culture. Oncology patients, serve as a potential population that might get advantage from SSCs Suspension-based FP. In mice studies demonstrated that transplant of just 20 leukaemic cells was sufficient to initiate malignant relapse [48]. Obviously these studies can't be conducted in humans, thus a threshold has not been found. Once SSCs transplantation arrives at the clinical stage, it would be essential to make sure that malignant cells do not get transplanted as well, that might be feasible with SSCs Suspension. Variety of groups have detailed technique for removal of malignant contamination from human Testicular cell Suspension [49]. Nevertheless, other populations without malignant problems like those with sickle cell disease getting hydroxyurea, might be the best candidates for SSCs transplantation, since there is no risk for malignant contamination as well as transfer.

\section{Sperm Generation Restoration}

\section{Autologous Methods}

After Brinster as well as Zimmermann [50], $1^{\text {st }}$ detailed successful SSCs transplantation into the seminiferous tubules of busulfan-sterilized mice during 1994, a lot of extra approaches as well as methods for Restoration of fertility have been shown. The chosen technique for SSCs transplantation in larger animals is via USG guided injection into the rete testis in view of easy accessibility as well as nearness to seminiferous tubules [51]. Homologous species transplantation of SSCs has yielded a live birth in larger mammals like goat as well as sheep [52]. Hermann et al. [53], documented in 2012 that recovery of Spermatogenesis following Autologous or allogenic SSCs transplantation into nonhuman primates who had infertility secondary to alkylating chemotherapy. Donor -obtained sperms had the capability of fertilizing eggs, resulting in preimplantaion embryo formation. Spermatogenesis further got restored in mice following SSCs transplantation, that had been cryopreserved for $>14 y$ rs [54], showing that cryopreservation does not impact SSCs function.

Till now, only 1 publication is there regarding Autologous SSCs transplantation in case of human males. 12 men had Testicular tissue removed as well as Testicular cell Suspension cryopreserved prior to gonadotoxic cancer treatment regards to Hodgkins lymphoma. Of these 7 of the men had their testicular cells injected into their testicular cells reinjected into 
"How Far Have We Reached with Regards to Our Endeavours in Testicular Tissue Transplantation Along with in Vitro Spermatogenesis After Success in Animals - A Systematic Review"

their Testis following total treatment finishing for their initial primary disease [51,55]. No follow up outcome was documented, to our misfortune.

One probable factor that limits SSCs transplantation, is the total amount of SSCs cells being little that might be observed in testis biopsies from prepubertal boys. Stem along with progenitor Spermatogonia, make up $0.3 \%$ of germ cells in mouse Testis as compared to $4 \%$ germ cells in monkeys as well as $22 \%$ of germ cells in human Testis [5, 56-]. Hence, the rare amount of SSCs might be lesser of a challenge in humans as compared to rodents. However, one can anticipate that escalating quantity of transplanted SSCs associates with is linked with higher engraftment as well as restoration of Spermatogenesis [44, 57].

Mouse SSCs cultures was initially detailed by KanatsuShinohara etal. [58], in 2003. They deposited Testicular cells on plates that were coated with gelatine. The Testicular somatic cells immediately stuck to the plate whereas floating germ cells could get aspirated as well as plated onto secondary plates. There was a double reason of this differential planting strategy of enriching SSCs, but higher significance is it deleted Testicular somatic cells which could fast overgrow the culture. Following 2 rounds of differential planting, floating cells got plated onto mouse embryonic fibroblast feeder cells in low serum medium that had been enriched with glial cell line-obtained neurotrophic factor (GDNF), fibroblast growthfactor2( FGF2), epidermal growth factor (EGF), as well as leukemia inhibitory factor( LIF). Functional SSCs expansion got corroborated when cultured cells regenerated Spermatogenesis following transplantation into infertile recipients as well as generating sperms which were competent enough to achieve fertilization as well as generate offspring [58]. This general method with several manipulations has been reproduced in multiple labs in mice as well as rats $[59,60]$.

Sadri-Ardekani et al. [61] were the $1^{\text {st }}$ who documented longterm culture of adult human SSCs, substances to a protocol quite the same to the situation detailed by Kanatsu-Shinohara etal. [58], for mouse SSCs cultures. Various plating got utilized to decrease somatic cells contamination, as well as the floating cells got passaged onto plates coated with human placental laminin $n$ Stem Pro medium that had been enriched with GDNF), fibroblast growth factor (FGF2), epidermal growth factor (EGF), as well as leukemia inhibitory factor
(LIF). They documented that human SSCs could get sustained for a lot of mths in culture with an 18, 000 times escalation in the population of transplantable SSCs >64days of culture. The researchers evaluated that successful SSCs transplantation needed only 110 times enhancement, depending on the biopsy size as well as effectiveness of colonization. The same group ultimately documented success prolongation of a culture with SSCs procured from prepubertal boys [62].

As per Murdoch et al. [63], on reviewing they observed $>20$ publications of human SSCs culture, that includes lots, which used conditions same as that initially by Kanatsu-Shinohara etal. [58], in mice as well as Sadri-Ardekani et al. [61], in humans. Few of these studies documented a significant expansion of human Spermatogonia in culture [64], whereas rest documented a fast decrease in the amount of human Spermatogonia utilizing these situations[65]. The altercation in these results can be reasoned by variations in the initiating cell populations and partly by various strategies utilized for evaluation of culture results, but conclusion is that more work is required with regards to human SSCs robust culture system development. As far as phenotype of human SSCs is concerned there exists minimum knowledge, which complicates the evaluation of culture results. Single cell sequencing studies done recently have developed a transcriptional atlas of germ cells as well as somatic atlas in human testis which might help in tackling this gap in knowledge [66].

Other Autologous transplantation way is de novo Testicular morphogenesis, an event by which heterologous Testicular cell Suspension possessing germ cells, sertoli cells, leydig cells, peritubular cells, as well as rest of testicular interstitial cells get transplanted with the anticipation that generation of functional Testis tissue [67]. Rat testicular cells that got cultured on extra cellular matrix gel as well as transplanted subcutaneous beneath the skin of immune-compromised mice formed structure looking like the seminiferous tubules as well as possessed Spermatogonia [68]. Following studies, done in pigs as well as sheep Testicular cell Suspension, which got pelleted as well as from prepubertal rhesus monkeys had transplanted beneath the immune-compromised nude mice developed normal seminiferous tubules possessing total Spermatogenesis [69]. In the same 
"How Far Have We Reached with Regards to Our Endeavours in Testicular Tissue Transplantation Along with in Vitro Spermatogenesis After Success in Animals - A Systematic Review"

way, Testis cells from prepubertal rhesus monkeys got transplantationinto the testis of irradiated adultrhesus monkeys along with reorganized into seminiferous tubules which displayed total Spermatogenesis following recovery 9mth following transplantation [70]. This method might be especially of utility in case of cancer cases who had got exposure to agents as well as which interfere with the normal functioning as well as testicular structure along with tubular cells. It might give an option of deletion of contamination from the cancer cells from the cell Suspension prior to transplantation. De novo Testicular morphogenesis, has not yet been documented in human subjects or utilizing human Testis tissues Certain advantage has been found utilizing orthotopic or ectopic grafting of intact testicular tissue bits in nonhuman species. Grafting of testicular tissue (like mouse to mouse ) or xenografts (say goat or pig to mouse )got initiated by Honaramooz et al., and then perfected [71]. in year 2002, who showed that immature human testicular tissue obtained from mice, goats or pigs could get matured for generation of total Spermatogenesis following grafting beneath the skin of recipient nude mice. Their group subsequently documented that Sperms from mouse grafts had the capacity to fertilize as well as produce an offspring [72]. Three studies further demonstrated that homologous or autologously grafting of prepubertal testicular tissue in nonhuman primates [73]. Total Spermatogenesis was found both from fresh as well as cryopreserved testicular tissue that had been grafted in the scrotum, but not beneath the skin of the back skin, probably secondary to the lesser temperature of the scrotum [73]. Function of the Sperms was not evaluated by the ability to fertilize as well as produce an offspring in these 3 studies.

In a more current study, the $1^{\text {st }}$ nonhuman primates offspring that was secondary to fertilization by graft-obtained Sperms has given birth [74]. Here prepubertal rhesus monkeys had castration followed by cryopreservation of the testicular tissue. Once puberty was attained by these monkeys, the testicular tissue was thawed and retransplanted beneath the skin of the back or the scrotal skin. These monkeys started generating Testosterone(T), pointing to normal functioning of the Hypothalamic-PituitaryTestosterone (H-P-T) axis inspite of just the presence of grafted testicular tissue in the back. All the grafts, be it the back sites or scrotal sites started generating sperms. Further Sperms obtained via the cryopreserved grafts got utilized for intracytoplasmic Sperm injection (ICSI), resulting in the healthy female offspring getting born. Despite Autologous grafting of testicular Tissue has not been evaluated in human beings, this study gives significant safety as well as probability data for aiding in further translation in human fertility centres.

\section{STRATEgies OUTSIDE THE Body}

In certain patient population, who remain at high probability of malignant contamination /those who will not undergo puberty, extracorporeal strategies like testicular Tissue culture / In vitro maturation as well as xenografting might give other strategies for Spermatogenesis. Sato etal. [75,76], in 2011 ist documented that took place through primitive Spermatogonia in neonatal mouse testicular tssue bits that had been culture in serum free media. Mouse Spermatozoa retrieved by this technique had same degree of DNA fragmentation, chromatin condensation, as well as aneuploidy like In vivo Spermatozoa, pointing that this event does not seem to have any harmful action on nuclear quality [77].

In human beings, total In vitro Spermatogenesis from SSCs to Spermatozoa has not taken place. Maximum differentiated germ cells obtained from immature testicular tissue is the spermatid stage [78]. A lot of studies have emphasized on the probable methods that might aid in overcoming the problems encountered during In vivo Spermatogenesis. As per Medano et al. [79], it was shown that if immature testicular tissue got cultured at a temperature of $34^{\circ} \mathrm{C}$, it decreased the degree of apoptosis rate within the tubules as well as caused a slowing of rate of alteration in morphogenesis as compared to immature testicular tissue cultured at a temperature of $37^{\circ} \mathrm{C}$. On exposure to follicle stimulating hormone (FSH)/luteinizing hormone (LH), enhanced amount of undifferentiated as well as premeiotic Spermatogonia having enhanced survival of sertoli cells, pointing that gonadotropin administration might be essential for efficacy in In vitro Spermatogenesis. Other trials to simulate the testicular niche with extra T, HCG, as well as retinoic acid lead to enhanced numbers of premeiotic Spermatogonia, that pointed that the supplementation of these might also facilitate differentiation of SSCs [80]. 
"How Far Have We Reached with Regards to Our Endeavours in Testicular Tissue Transplantation Along with in Vitro Spermatogenesis After Success in Animals - A Systematic Review"

One significant process that takes place at the initiation of In vivo Spermatogenesis (or puberty is the development of the Blood-testis barrier (BTB), that has a key part in Spermatogenesis[81]. Mice possessing knockouts or mutations in the BTB proteins mostly present with aberrations in Spermatogenesis [82], as well as it is feasible that humans having similar aberrations would also present with subfertility. Expression of BTB structural proteins connexion 43 as well as claudin 11 within In vitro testicular culture, pointing that BTB generation even takes place outside of natural testis, was seen by De Michaele et al. [83], despite that, what it suggest is not clear.

Generation of testicular organoids, utilizing threedimensional cultures system might even aid in more specific replication of the SSCs niche, in a manner that can't be achieved in 2D cultures [81,84]. A biological scaffold was engineered by Baert etal. [85], in 2014 by managing to decellularize human cadaveric testicular tissue. Utilizing testicular tissue from adults as well as prepubertal boys for populating this scaffold caused a Long-term proliferation of both early as well as late Spermatogonia [86]. A different platform as compared to the biological scaffold is the three-layer gradient system that was posited by Alves-Lopes JP et al. [87], that Utilizes two matrigel layers that surrounded a matrigel plus testicular cell layer to better reform the BTB as well as concentration gradients that are observed In vivo. A microwell aggregation system was recently documented by Sakib et al. [88], with the idea of redeveloping the In vivo relation ships between germ cells, sertoli cells as well as interstitial cells. This study evaluated utilizing prepubertal testicular cell Suspension from humans, primates, pigs as well as mice, that got centrifugated in microwells possessing culture system, that lead to the generation of the seminiferous tubules epithelium as well as interstitium that was separated by a basement membrane. The orientation of the seminiferous tubules in that particular study was inside out, but the system might give a significant platform for evaluating testicular morphogenesis or a high throughput platform of toxicity testing.

Xenografting of testicular tissue obtained from prepubertal mice, pig, goats as well as nonhuman primates into immune compromised nude mice lead to the generation of sperms having the capacity to fertilize as well as produce an offspring [71, 89]. Despite simulating work has been conducted in humans utilizing fragments of testicular tissue, total Spermatogenesi s following Xenografting into nude mice has not been seen, probably secondary to the phylogenetic variations among humans as well as mice [90]. Lately, successful harvest of Spermatozoa utilizing Xenografted prepubertal macaque testistissue resulted in LB of a primate [91]. A posit has been given that Xenografting of testicular tissue into the mouse testis parenchyma as compared to subcutaneously, better aided in differentiation of Spermatogonia into spermatids as well as Spermatozoa, possibly secondary to favouring temperature control as well as paracrine support [92]. Still it is not clear if an intermediate path towards clinical applicability utilizing animal intermediates exists [93], however there is a precedent in other ways, as shown by Gassei etal. [94]. Moreover in certain cases where there is risk regards to malignant contamination of the tissue, Xenografting might turn out to be safer technique. Testicular tissue Xenografting might also be a significant method for transgender females who would not undergo male puberty and thus would not be able to mature testicular tissue inside their own bodies.

\section{FUTURE WORK NEEDED}

All the explained approaches are in different stages of experimental programs as well as clinical use. The only method that had been tried in humans is the Autologous SSCs transplantation [32], but results of the trial have not been documented. This technique has been evaluated in mammals that include nonhuman primates where Spermatogenesis utilizing these sperms has been visualized [52, 53]. For Long-term SSCs culture, independent protocols are required for replication for translation of this technique into the clinical scenario [67]. The biggest problem faced with this method is the lack of a functional assay for finding a molecular marker that is particular to SSCs [95] or utilize humans to nude mice Xenografting in the form of a functional assay [61-63], [96, 97].

Autologous grafting of testicular tissue might further immediately be prepared for clinical use in humans. This method has led to the LB of nonhuman primates offspring [74]. 1 of the biggest drawback of this method has been the castration of the subjects prior to grafting, that obviously is not feasible in human looking for FP. Future research pointing to the safety as well as efficacy, of testicular tissue grafting in case 
"How Far Have We Reached with Regards to Our Endeavours in Testicular Tissue Transplantation Along with in Vitro Spermatogenesis After Success in Animals - A Systematic Review"

of primates that are going to act as recipients are not castrated prior to the study before we can try these type of work in humans. In case of humans for conducting testicular tissue grafting, selection criteria would need a lot of caution, like those presenting with no malignancy or solid tumors, since this would decrease the chances of reintroduction of malignant cells to the patient. transgender females getting hormone treatment would further not get help from this strategy since they would not go through male puberty.

Inspite of promising outcomes, the other approaches detailed here, it is quite distant from clinic. Prior to 2016 one of the biggest problems with regards to Xenografting, was the absence of visual Sperm generation in case of nonrodent models. Nevertheless, Spermatogenesis as well as an offspring with the utilization of primates testicular tissue grafted in mice has got detailed recently [91]. No report of spermatogenesis has been documented utilizing Xenografted human functional tissue, thus that is needed prior to use in clinical scenario. More work will be required to check the risk of Xenogenic virus transmission on utilizing Xenograft-obtained sperm.

There are some inherent benefits in humans with regards to In vitro Spermatogenesis, that are it does not carry a chance of malignant cells re-entry or retroviral infection (like in testicular tissue grafting as well as Xenografting respectively). Despite total In vitro Spermatogenesis right from SSCs to Spermatozoa has been demonstrated in mice, these outcomes could not be replicated in case of primates as well as humans. Haploid cells at the round spermatid stage have been seen utilizing in vitro cultures of immature human testicular tissue[78], Nevertheles, the epigenetic/ genetic normalcy along with fertilization ability of these cells could not be checked, it might be feasible to utilize In vitro generated spermatids or sperms for fertilization as well as embryo generation $[98,99]$. Proper characterisation of these post meiotic germ cells as well as checking for their fertility ability in primates would be required prior to coming into the clinical scenario.

\section{CONCLUSIONS}

At present there are no methods that are present for men who have inability of Generating mature, functional sperm. Nevertheless, some are almost prepared for being launched for trials in humans.
Utilizing the minimal tissues that are there that can be utilized; it is probable that one or more of these treatments enter the clinical atmosphere by the next decade hopefully. Further Braye et al. [100], has studied doing cryopreservation of 112 pts prepubertal whose tissue is cryopreserved although none had tissues retransplanted back, thus we do not have the results of upto 16 years of cryopreservation in humans. [100] Young boys undergoing gonadotoxic treatments are at high risk of spermatogonial stem cell (SSC) loss and fertility problems later in life. Stem cell loss can also occur in specific genetic conditions, eg, Klinefelter syndrome (KS). Before puberty, these boys do not yet produce sperm. Hence, they cannot benefit from sperm banking. An emerging alternative is the freezing of testicular tissue aiming to preserve the SSCs for eventual autologous transplantation or in vitro maturation at adult age. Many fertility preservation programmes include cryopreservation of immature testicular tissue, although the restoration procedures are still under development. Until the end of 2018, the Universitair Ziekenhuis Brussel has frozen testicular tissues of 112 patients between 8 months and 18 years of age. Testicular tissue was removed in view of gonadotoxic cancer treatment (35\%), gonadotoxic conditioning therapy for bone marrow transplantation (35\%) or in boys diagnosed with KS (30\%). So far, none of these boys had their testicular tissue transplanted back. They have thus summarized their experience with cryopreservation of immature testicular tissue over the past 16 years (2002-2018) and describes the key issues for setting up a cryopreservation programme for immature testicular tissue as a means to safeguard the future fertility of boys at high risk of SSC loss and lets hope this opens the pandoras box for this type of help for male fertility [100].

\section{REFERENCES}

[1] Niederberger C, Pellicer A, Cohen J, Gardner DK, Palermo GD, O'Neill CL, etal. Forty years of IVF. Fertil Steril 2018; 110:185-324. e5.

[2] DeRooij DG. The nature and dynamics of Spermatogonial Stem Cells. Development 2017; 144: 3022-30.

[3] Fayomi AP, Orwig KE. Spermatogonial Stem Cells niche unit in mammalian testes. Physiol Rev 2012; 92:577-95. 
"How Far Have We Reached with Regards to Our Endeavours in Testicular Tissue Transplantation Along with in Vitro Spermatogenesis After Success in Animals - A Systematic Review"

[4] Ehmcke J, Simorangkir DR, Schlatt S. Identification of the starting point of Spermatogenesis and characterization of the testicular Stem Cell in adult male rhesus monkeys. Hum Reprod 2005; 20:1185-93.

[5] Von Kopylow K, Staege H, Spiess AN, Schulze W, Will H, Primig M, etal. differential marker protein expression specifies rarefaction zone containing human Adark Spermatogonia. Reproduction 2012; 143: 45-57.

[6] Pelzman DL, Orwig KE, Hwang K. Progress in translational reproductive science: testicular tissue transplantation and In vitro Spermatogenesis. Fertil Steril 2020; 113(3): 500-9.

[7] Heinrich A, Defalco T. Essential roles of interstitial cells in Testicular Development and function. Andrology 2019. http://doi. org/10. 111/andr. 12703.

[8] Makela JA, Hobbs RM,. Molecular regulation of Spermatogonial Stem Cells renewal and differentiation. Reproduction 2019; 158:169-87.

[9] Kulvinder Kochar Kaur, Allahbadia GN, Singh M. An Update on Management of Oncofertility-Does the Use of Vsels Appear Practical in the Near Future in Human Malignancies Replacing Cortical Tissue/Testicular Tissue Transplantation. Int J Stem Cell Regen Med2019; 1(1): 103

[10] Yoshida S, Sukeno M, Nabeshima YI. A-vasculature associated niche for undifferentiated Spermatogonia in the mouse testis. Science 2007; 317: 1722-6.

[11] Johnson EK, Finlayson C, Rowell EE, Goosiengfiao Y,Pavone ME, LockartB, etal.Fertility Preservation for paediatric patients:current state and future possibilities. J Urol 2017; 198:186-94.

[12] Oktay K, Harvey BE, Partridge AH, Quinn GP, Reinecke J, Taylor HS, etal. , and testes. Fertility Preservation in patients with cancer: ASCO clinical practice guideline update. J Clin Oncol 2018; 36:1994-2001.

[13] Meistrich ML. Effects of chemotherapy and radiotherapy on Spermatogenesis in humans. Fertil Steril 2013; 100:1180-6.
[14] Green DM, Liu W, Kutteh WH, Ke RW, Shelton KC, Sklar CA, etal. , Cumulative alkylating agents exposure and semen parameters in adult survivors of childhood cancers :a report from the St Jude Lifetime cohort study. Lancet Oncol 2014; 15:1215-23.

[15] Ethics Committee of the American Society of reproductive Medicine. Fertility Preservation and Reproduction in patients facing gonadotoxic therapies:an Ethics Committee opinion. Fertil Steril 2018; 110:380-6.

[16] Grover NS, Deal AM, Wood WA, Mersereau JE. Young men with cancers experience low retrieval rates for Fertility counselling and Sperm Banking. J Oncol Pract2016; 12:465-71.

[17] Ethics Committee of the American Society of reproductive Medicine. Access to Fertility services by transgender persons: an Ethics Committee opinion. Fertil Steril 2015; 104:1111-5.

[18] Menon S, Rives N, Mousset -Simeon N, Sibert L, Vannier JP, Mazurier S, etal. Fertility Preservation in adolescent males :experience over 22 years at Rouen University hospital. Hum Reprod 2009; 24:37-44.

[19] Abram McBride J, Lipscultz LI. Male Fertility Preservation. Curr Urol Rep 2018; 19:49.

[20] Feldschuh J, Brassel J, Durso N, Levine A. Succesful sperm storage for 28 years. Fertil Steril 2005; 84: 1017.

[21] Szell AZ, Bierbaurn RC, Hazelrigg WB, Chetkowski RJ. Live births from frozen human semen stored for 40 years. J Assist Reprod Genet 2013; 30: 743-4.

[22] Ferrari S, Paffoni A, Filippi F, Busnell A, Vegetti W, Simigliana E. Sperm cryopreservation and Reproductive outcome in Male cancer patients :a systematic review. Reprod Biomed Online 2016; 33:29-38.

[23] Huang C, Lei L, Wu HL, Gan RX, Yuan XB, Fan LQ, etal. Long term cryostorage of a human sperm Bank does not affect clinical outcomes. Fertil Steril 2019; 112:663-9. e1

[24] Mehta A, Sigman M. Management of the dry ejaculate:a systematic review. Of aspermia and retrograde ejaculation. Fertil Steril 2015; 104:1074-81. 
"How Far Have We Reached with Regards to Our Endeavours in Testicular Tissue Transplantation Along with in Vitro Spermatogenesis After Success in Animals - A Systematic Review"

[25] Halpern JA, Hill R, Brannigan RE. Guideline based approach to male Fertility Preservation. Urol Oncol 2020; 28:31-5.

[26] Berookhim BM, Mulhall JP. Outcomes of Sperm retrieval strategies for Fertility Preservation. among males scheduled to undergo cancer treatment. Steril 2014; 101:Fertil 805-11.

[27] Moss JL, Choi AW, Fitzgerald Keeter MK, Brannigan RE. Male Adolescent Fertility Preservation. Fertil Steril 2016; 105:267-73.

[28] Leonard M, Hammelef K, Smith GD. Fertility considerations, counselling, and semen cryopreservation for males prior to the initiation of cancer therapy. Clin J Oncol Nurs 2004; 8:127$31,145$.

[29] Burns KC, Hoefgen H, Strine A, Dasgupta R. Fertility Preservation options in paediatric and Adolescent patients with cancer: Fertility options in paediatric patients. Cancer 2018; 124: 1867-76.

[30] DiNofia AM, Wang X, Yannekis G, Ogle S, Hobble WL, Carlson CA, etal. Analysis of semen parameters in a young cohort of cancer patients. Paediatr Blood Cancer 2017; 64:381-6.

[31] Valli-Pulaski H, Peters KA, Gassei K, Steimer SR, Sukhwani M, HermannBP, etal. Testicular tissue cryopreservation: 8 years of experience from a coordinated network of academic centers. Hum Reprod 2019; 34:966-77.

[32] Radford J. Restoration of Fertility after treatment of cancer. Horm Res 2003; 59(Suppl1):21-3.

[33] Anger JT, Gilbert BR, Goldstein M. Cryopreservation of Sperm:indications. methods and results. J Urol 2003; 170:1079-84.

[34] Thompson LK, Fleming SD, Aitken RJ, De Luis GN, ZieschangJA,Clark AM. Cryopreservation induced human Sperm DNA damage is predominantly mediated by oxidative stress rather than apoptosis. Hum Reprod 2009; 24:2061-70.

[35] Ozkavukcu S, Erdemli E, Isik A, Oztuna D, Karahusey inoglu S. Effects of Cryopreservation on Sperm parameters and ultrastructural morphology of human Spermatozoa. J Assist Reprod Genet 2008; 25:403-11.
[36] MacKenna A, Crosby J, Huidobo C, Correa E, Duque G. Semen quality before cryopreservation and after thawing in 543 patients with Testicular cancer. JBRA Assist Reprod 2017; 21:31-4.

[37] Lusignani MF, Li X, Herrero B, Delbes G, Chan PTK. Effects of different Cryopreservation methods on DNA integrity and Sperm chromatin quality in men. Andrology 2018; 6:829-35.

[38] Li YX, Zhou L. Lv MQ, Ge P, Liu YC, Zhou D. Vitrification and Conventional freezing Methods in sperm ryopreservation:a systematic review and meta -analysis. Eur J Obstet Gynecol Reprod Biol 2019; 233:84-92.

[39] Le MT, Nguyen TTT, Nguyen TT, Nguyen VT, Nguyen TTA, Nguyen TQH, etal. C ryopreservation srof human Spermatozoa. By Vitrification versus conventional rapid freezing :effects on motility, viability, morphology and cellular defects. Eur J Obstet Gynecol Reprod Biol 2019; 234:14-20.

[40] O'Neill HC, Nikoloska M, Ho H, Doshi A, Maalouf W. Improved Cryopreservation of Spermatozoa usingVitrification:comparison ofCryoprotectants and a novel device for long term storage. J Assist Reprod Genet 2019; 36:1713-20.

[41] Spis E, , Bushkovasla A, Isachenkho E, Todorov P, Sanchez R, Skopets V, etal. Conventional rapid freezing versus Cryoprotectants -free Vitrification of epidydymal (MESA) and Testicular (TESE) Spermatozoa :three live births. Cryobiology 2019; 90:100-2.

[42] Poels J, Van Langendonckt A, Many MC, Wese FX, Wyns C. Vitrification preserves proliferation capacity in human Spermatozoa. Hum Reprod 2013; 28:578-89.

[43] Karlsson JO, Toner M. Long-term storage of tissues by Cryopreservation :critical issues. Biomaterials 1996; 17:243-56.

[44] Kanbar M, De Michele F, Wyns C. Cryo storage of testicular tissues and retransplantation of Spermatogonial Stem Cells in the infertile male. Best Pract Res Clin Endocrinol Metab 2019; 33:103-15.

[45] Unni S, Kasiviswanathan S, D'Souza S, Khavale S, Mukherjee S, Patwardhan S, etal. Efficient Cryopreservation of testicular tissues: effect 
"How Far Have We Reached with Regards to Our Endeavours in Testicular Tissue Transplantation Along with in Vitro Spermatogenesis After Success in Animals - A Systematic Review"

of age, sample state, and concentrate of cryoprotectant. Fertil Steril 2012; 97:200-8. e1.

[46] Yango P, Altman E, Smith JF, Klatsky PC, Tran ND. Optimizing Cryopreservation of human Spermatogonial Stem Cells comparing the effectiveness of testicular tissues and single cell Suspension cryopreservation. Fertil Steril 2014; 102:1491-8. e1.

[47] Guo J, Cairns BR, Isolation and enrichment of Spermatogonial Stem Cells from human testis tissues. Curr Protoc Stem Cell Biol 2019; 49:e77.

[48] Jahnukainen K, Hou M, Petersen C, Setchell B, Soder O. Intra testicular transplantation of testicular cells from leukaemic rats causes transmisson of leukaemia. Cancer Res 2001; 61:706-10.

[49] Sadri-Ardekani H, Hoimburg CH, Van den Berg H, Van der Veen F, Van de Schoot C, etal. Eliminating acute lymphoblastic leukaemia cells from a testicular cell culture s:a pilot study. Fertil Steril 2014; 101:1072-8. e1.

[50] Brinster RL, Zimmermann JW. Spermatogenesis following male germ cells transplantation. Proc Natl Acad Sci USA1994; 91:11298-302.

[51] Schlatt S, Rosiepen G, Weibauer GF, Rolf C, Brook PF, Nieschlag E. Germ cell transfer into rat, bovine, monkey and human testis. Hum Reprod 1999; 14:144-50.

[52] Herrid M, Olejnik J, Jackson M, Suchowerska N, StockwellS, Davey R, etal. Irradiation enhances the Efficiency of testicular germ cells transplantation in sheep. Biol Reprod 2009; 81:898-905.

[53] Hermann BP, Sukhwani M, Winkler F, Pascarella JN, Peters KN, Sheng Y, etal. Spermatogonial Stem Cells transplantation in rhesus testis regenerates Spermatogenesis producing functional Sperms. Cell Stem Cell 2012; 11:715-26.

[54] Wu X, Goodyear SM, Abramowitz LK, Bartolomei MS, Tobias JW, Avarbock MR, etal. Fertile offspring derived from mouse Spermatogonial Stem Cells Cryopreserved for more than 14 years. Hum Reprod 2012; 27:1249-59.
[55] Radford J, Shalet S, Leberman B. Fertility after treatment for cancer:questions remain over ways of preserving ovarian and testicular tissues. BMJ 1999; 319:935-6.

[56] Hermann BP, Sukhwani M, Simorangkir DR, Chu T, Plant TM, Orwig KE. Molecular dissection of the male germ cells lineage identifies putative Spermatogonial Stem Cells in rhesus macaques. Hum Reprod 2009; 24:1704-16.

[57] Dobrinsky I, Ogawa T, Avarbock MR, Brinster RL. Computer assisted image analysis to assess colonization of Spermatogonial multiplication and Stem Cells renewal in the C3H/101F1hybrid mouse. Mutat Res 1993; 53:142-8.

[58] Kanatsu-Shinohara M, Ogonuki N, Inoue K, Miki H, Ogura A, Toyokuni S, etal. Long-term proliferation in culture and germline transmission of mouse male germline Stem Cells. Biol Reprod 2003; 69:612-6.

[59] Ryu BY, Kubota H Avarbock MR, Brinster RL. Conservation of Spermatogonial Stem Cells self renewal signalling between mouse and rat. Proc Natl Acad Sci USA2005; 102:14302-7.

[60] Kaucher AV, Oatley MJ, Oatley JM. NEUROG3 is a critical downstream effector of STAT3 -regulated differentiation of mammalian Stem and progenitor Spermatogonia. Biol Reprod 2012; 86: 1-11.

[61] Sadri-Ardekani H, Mizrak SC, Van daalen SKM, Korver CM, Roepers-Gajadien HL, Koruji M, etal. Propagation of human Spermatogonial Stem Cells in vitro. JAMA 2009; 302:2127-34.

[62] Sadri-Ardekani H, Akhondi MA, Van der Veen F, Repping S, Van Pelt AMM. In vitro propagation of human prepubertal Spermatogonial Stem Cells. JAMA 2009; 302:2127-34.

[63] Murdoch MH, David S, Swine hart IT, Reing JE, Tran K, Gassei K, etal. Human extra cellular matrix enhances Human Spermatogonial Stem Cells in vivo. Tissue Eng Part A2019; 25:663-76.

[64] Kokkinaki M, Djourabtchi A, Gole staneh N. Long-term culture of Human SEEA-4 positive 
"How Far Have We Reached with Regards to Our Endeavours in Testicular Tissue Transplantation Along with in Vitro Spermatogenesis After Success in Animals - A Systematic Review"

Spermatogonial Stem Cells (SSC's). J Stem Cell

Res Ther 2011; 2:2488.

[65] Medrano JV, Rombaut C, Simon C, Pellicer A, Goosens E. Human Spermatogonial Stem Cells display limited proliferation in vitro under mouse Spermatogonial Stem Cells culture conditions. Fertil Steril 2016; 106:1539-49. e8.

[66] Guo J, NieX, Giebler M, Micochova H, Wang Y, Grow EJ, etal. The dynamic transcriptional cell atlas of testis development during human puberty. Cell Stem Cell 2020; 26:1-15.

[67] Gassei K, Orwig KE. Experimental methods to preserve male fertility and treat male factor fertility. Fertil Steril 2016; 105:256-66.

[68] Gassei K, Schlatt S, Ehmcke J. Denovo morphogenesis of seminiferous tubules from dissociated from immature rat testicular cells in xenografts. J Androl 2006; 27:611-8.

[69] Arregui L, Rathi R, Megee SO, Honoramooz A, Gomendio M, Roldan ERS, etal. Xenografting of sheep Testis tissue and isolated cells as a model for preservation of genetic material from endangered ungulates. Reproduction 2008; 136: 85-93.

[70] Shetty G, Mitchell JM, Lam TNA, Wu Z, Zhang J, Hill L, etal. Donor Spermatogenesis in Denovo formed semini ferous tubules from transplanted Testicular cells in rhesus monkeys Testis. Hum Reprod 2018; 33:2249-55.

[71] Honaramooz A, Snedaker A, Boiani M, Scholer H, Dobrinsky I, Schlatt S. Sperm from neonatal mammalian testis grafted in mice. Nature 2002; 418:778-81.

[72] Schlatt S, Honaramooz A, Boiani M, Scholer H, Dobrinsky I. Progeny from Sperm obtained after ectopic grafting of neonatal mouse testis 1. Biol Reprod 2003; 68:2331-5.

[73] Luetjens CM, Stukenborg JB, Nieschlag E, Simoni M, Wistuba J. Complete Spermatogenesis in orthotopic but not ectopic transplants of Autologously grafted marmoset testicular Tissue. Endocrinology 2008; 149:1736-47.

[74] Fayomi AP, Peters K, Sukhmami M, Valli-Pulansky H, Shetty G, Meistrich ML, etal. Autologous grafting of cryopreserved prepubertal rhesus testis produces Sperm and offspring. Science 2019; 363:1314-9.

[75] Sato T, Katagiri K, Kubota Y, Ogawa T. In vitro Sperm production from mouse Spermatogonial Stem Cell lines using an organ culture method. Nat Protoc 2013; 8:2098-104.

[76] Sato T, Katagiri K, Gohbara A, Inoue K Ogonuki $\mathrm{N}$, , Miki H, Ogura A, etal. In vitro production of functional Sperm in cultured neonatal mouse testis. Nature 2011; 471:504-7.

[77] Obelette A, Rives N, Dyumont L, Rives A, Verghaese F, Jurmeau F, etal. Assessment of Sperm nuclear quality after In vitro maturation of fresh or fresh or frozen /thawed mouse prepubertal testis. Mol Hum Reprod 2017; 23:674-84.

[78] Abofoul -Azab M, Abumadhighem A, Lunenfeld E, Kapelushnik J, Shi Q, Pinkas H, etal. Development of post meiotic cells. In vitro from Spermatogonial Cells of prepubertal cancer patients. Stem Cells Dev 2018; 27:1007-20.

[79] Medrano JV, Vilanova -Perez T, Fernez-Ferrer V, Navarro-Gomezlechon A, Martinez-Tiguero ML, Garcia S, etal. Influence of temperature, serum and gonadotropin supplementation in short and longterm organotypic culture of human immature testicular tissue. Fertil Steril 2018; 110: 1045-57. e3.

[80] De Michaele F, Poels J, Weerens L, Petit C, Evrard Z, Ambroise J, etal. Preserved semini ferous tubules integrity with Spermatogonial survival and induction of sertoli and, leydig cells maturation after longterm organotypic culture of prepubertal human testicular tissue Hum Reprod 2017; 32:i32-45. 
"How Far Have We Reached with Regards to Our Endeavours in Testicular Tissue Transplantation Along with in Vitro Spermatogenesis After Success in Animals - A Systematic Review"

[81] Giudice MG, De Michaele F, Poels J, Vermuelen M, Update on Fertility restoration from prepubertal Spermatogonial Stem Cells: how far are we from clinical practice ? Stem Cells Res 2017; 21: 171-7.

[82] Jiang XH, Bukhari I, Zheng W, Yin S, Wang $\mathrm{Z}$, Cooke HJ J, etal. Blood-testis barrier and Spermatogenesis :lessons from genetically modified mice. Asian J Androl 2014; 16:572-80.

[83] De Michaele F, Poels J, Giudice MG, De Smedt F, Ambroise J, Vermuelen M, etal. In vitro formation of the Blood-testis barrier during longterm organotypic culture of prepubertal human testicular tissue: comparison with a large cohort of prepubertal boys. MHR Basic Sci Reprod Med 2018; 24: 271-82.

[84] Pendergraft SS, Sadri-Ardekani H, Atala A, Bishop CE. Three-dimensional testicular organoid: a novel tool for the study of human Spermatogenesis and gonadotoxicity in vitro. Biol Reprod 2017; 96:720-32.

[85] Baert Y, Stukenborg JB, Landreh M, De Kock J, Jornvall H, Soder O, etal. Derivation and characterisation of of cytocompatible scaffold from human testis. Hum Reprod 2015; 30: 256-67.

[86] Baert Y, De Kock J, Alves-Lopes JP, SoderO, Stukenborg JB, Goosens E, etal. Primary human testicular cells self organize into organoids with testicular properties. Stem Cells Rep 2017; 8: 30-8.

[87] Alves-Lopes JP, SoderO, Stukenborg JB. Testicular organoids generation by a novel In vitro Threelayer gradient system. Biomaterials 2017; 130: 76-89.

[88] Sakib S, Uchida A, Valenzuela-Leon P, Yu Y, Valli-Pulansky H, Orwig KE, etal. Formation of organotypic Testicular organoids in microwell culture. Biol Reprod 2019; 100:1648-60.
[89] Honaramooz A, LiMW, Penedo MCT, Meyers S, Dobrinsky I. Accelerated maturation of Primate testis by xenografting into mice. Biol Reprod 2004; 70:1500-3.

[90] Wyns C, VanLangendonct A, Wese FX, Donnez J, Curaba M. Long-term Spermatogonial survival in cryopreserved and xenografted immature human testicular tissue. Hum Reprod 2008; 23:2402-14.

[91] Liu Z, Nie YH, Zhang CC, Cai YJ, Wang Y, Lu HP, etal. Generation of macaques with sperms derived from juvenile monkey testicular xenografts. Cell Res 2016; 26:139-42.

[92] Ntemou E, Kadam P, Van Seen D, Wistuba J, Michaele RT, Schlatt S, etal. Complete Spermatogenesis in intra testicular testis tissue xenotransplants from immature nonhuman primates. Hum Reprod 2019; 34:403-13.

[93] Nellore A, Fishman JA. Donor-derived infections and infectious risks in xenotransplantation and allo transplantation. Xenotransplantation 2018; 25:e12423.

[94] Gassei K, Shaw PH, Cannon GM, Meacham LR, Orwig KE. Male Fertility Preservation:current options and advances in research. In Woodruff TK, Gosiengfiao YC editors. Pediatric and Adolescent Oncofertility. Cham, the Netherlands :Spring International 2017; 119-42.

[95] Kubota Y, Brinster RL. Spermatogonial Stem Cell. Biol Reprod 2018; 99:52-74.

[96] Neuhans N, Yoon J, Terwart N, Kliesch S, SaggewissJ, Huge A, etal. Single Cell gene analysis reveals diversity among human Spermatogonia. Mol Hum Reprod 2017; 23:79-90.

[97] Valli- H, Sukhmami M, Dovey SL, Peters KA, Donohue J, Castro CA, etal. Fluorescence and magnetic activated cell sorting strategies to isolate and enrich human Spermatogonial Stem Cells. Fertil Steril 2014; 102:566-80. e7. 
"How Far Have We Reached with Regards to Our Endeavours in Testicular Tissue Transplantation Along with in Vitro Spermatogenesis After Success in Animals - A Systematic Review"

[98] Barak Y, Kogosowski A, Goldman S, Saffer Y, born after round spermatid injection into human Gonen Y, GTTesarik J. Pregnancy and birth after oocytes. Proc Natl Acad Sci USA2015; 112: 4629-34. transfer of embryos that developed from single nucleated zygotes obtained by injection of round spermatid into human oocytes. Fertil Steril 1998; 70:67-70.

[99] Tenaka A, Nagayoshi M, Takemoto Y, Tanaka I, Kusunoki H, Watanabe S, etal. Fourteen babies

[100] Braye A, Tournaye H, Goosens E. Setting up a Cryopreservation programme for immature testicular tissue: lessons learnt after more than 15 years of experience. Clin Med Insights Reprod Health 2019; 13 13: 1179558119886342. doi: $10.1177 / 1179558119886342$.

Citation: Dr. Kulvinder Kochar Kaur, Dr. Gautam Allahbadia, Dr. Mandeep Singh. How Far Have We Reached with Regards to Our Endeavours in Testicular Tissue Transplantation Along with in Vitro Spermatogenesis After Success in Animals - A Systematic Review. Archives of Urology. 2020; 3(2): 1-15.

Copyright: (C) 2020 Dr. Kulvinder Kochar Kaur, Dr. Gautam Allahbadia, Dr. Mandeep Singh. This is an open access article distributed under the Creative Commons Attribution License, which permits unrestricted use, distribution, and reproduction in any medium, provided the original work is properly cited. 